\section{(2) \\ BRAZIILIAN JOURNAL \\ OF MEDICAL AND BIOLOGICAL RESEARCH}

www.bjournal.com.br
ISSN 0100-879X

Volume 45 (3) 179-290 March 2012

BIOMIEDICAL SCIENCES

AND

CLINICAL INVESTIGATION

Braz J Med Biol Res, March 2012, Volume 45(3) 256-263

doi: $10.1590 / \mathrm{S} 0100-879 X 2012007500018$

Cardiopulmonary exercise testing variables as predictors of longterm outcome in thoracic sarcoidosis

A.J. Lopes, S.L.S. Menezes, C.M. Dias, J.F. Oliveira, M.R.M. Mainenti and F.S. Guimarães

The Brazilian Journal of Medical and Biological Research is partially financed by

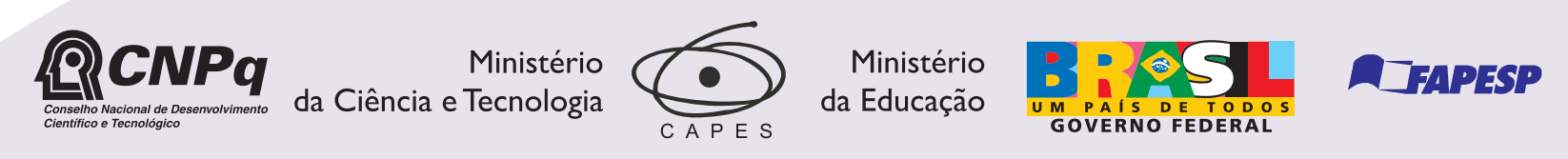

Institutional Sponsors

Sciezo
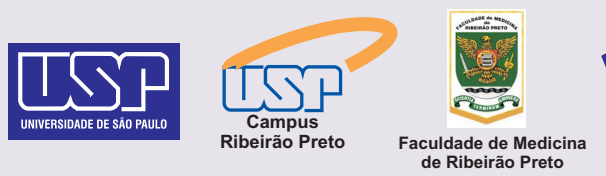

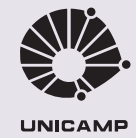

UNICAMP $\oplus$ SHIMADZU

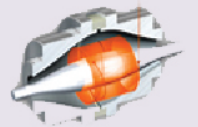

1DI Associaçāo Explore High - Performance MS Orbitrap Technology In Proteomics \& Metabolomics analitica $\underset{\text { analiticaweb.com.br }}{\text { Thermo }}$ 


\title{
Cardiopulmonary exercise testing variables as predictors of long-term outcome in thoracic sarcoidosis
}

\author{
A.J. Lopes ${ }^{1,2}$, S.L.S. Menezes ${ }^{2,3}$, C.M. Dias², J.F. Oliveira², M.R.M. Mainenti² \\ and F.S. Guimarães ${ }^{2,3}$
}

${ }^{1}$ Setor de Provas de Função Respiratória, Universidade do Estado do Rio de Janeiro, Rio de Janeiro, RJ, Brasil 2Programa de Pós-Graduação em Ciências da Reabilitação, Centro Universitário Augusto Motta,

Rio de Janeiro, RJ, Brasil

${ }^{3}$ Curso de Fisioterapia, Universidade Federal do Rio de Janeiro, Rio de Janeiro, RJ, Brasil

\begin{abstract}
Cardiopulmonary exercise testing (CPET) plays an important role in the assessment of functional capacity in patients with interstitial lung disease. The aim of this study was to identify CPET measures that might be helpful in predicting the vital capacity and diffusion capacity outcomes of patients with thoracic sarcoidosis. A longitudinal study was conducted on 42 nonsmoking patients with thoracic sarcoidosis (median age $=46.5$ years, 22 females). At the first evaluation, spirometry, the measurement of single-breath carbon monoxide diffusing capacity ( $\left.\mathrm{D}_{\mathrm{LCOsb}}\right)$ and CPET were performed. Five years later, the patients underwent a second evaluation consisting of spirometry and $D_{\text {LCOsb }}$ measurement. After 5 years, forced vital capacity (FVC) $\%$ and $D_{\text {LCOsb }} \%$ had decreased significantly [95.5 (82-105) vs 87.5 (58-103) and 93.5 (79-103) vs 84.5 (44-102), respectively; P < 0.0001 for both]. In CPET, the peak oxygen uptake, maximum respiratory rate, breathing reserve, alveolar-arterial oxygen pressure gradient at peak exercise $\left(\mathrm{P}(\mathrm{A}-\mathrm{a}) \mathrm{O}_{2}\right)$, and $\Delta \mathrm{SpO}_{2}$ values showed a strong correlation with the relative differences for $\mathrm{FVC} \%$ and $\mathrm{D}_{\mathrm{LCOsb}} \%(\mathrm{P}<0.0001$ for all). $\mathrm{P}(\mathrm{A}-\mathrm{a}) \mathrm{O}_{2} \geq 22 \mathrm{mmHg}$ and breathing reserve $\leq 40 \%$ were identified as significant independent variables for the decline in pulmonary function. Patients with thoracic sarcoidosis showed a significant reduction in FVC\% and $\mathrm{D}_{\mathrm{LCO}} \mathrm{F} \%$ after 5 years of follow-up. These data show that the outcome measures of CPET are predictors of the decline of pulmonary function.
\end{abstract}

Key words: Sarcoidosis; Exercise; Respiratory function tests; Respiratory mechanics

\section{Introduction}

Sarcoidosis is a multisystem granulomatous disease of unknown origin that occurs in mediastinal and pulmonary sites in $90 \%$ of cases. The clinical course varies widely. Parenchymal abnormalities often resolve spontaneously, but progress toward pulmonary fibrosis in $20-25 \%$ of cases (1).

Clinicians frequently find it difficult to manage patients with thoracic sarcoidosis due to the significant variability in disease manifestation and multiple, non-specific symptoms. Pulmonary function tests (PFTs) are important for measuring initial lung impairment and providing a baseline to assess improvement or deterioration of lung disease. In clinical practice, the most common parameters that indicate functional impairment are forced vital capacity (FVC) and single-breath diffusion of carbon monoxide across the lung
$\left(D_{\text {LCOsb }}\right)$; these measures are often combined with radiological assessment. However, the management of some patients requires a thoracic computed tomography scan and further physiological measurements, including exercise testing (2). Cardiopulmonary exercise testing (CPET) provides an accurate assessment of functional capacity in patients with interstitial lung disease, allowing the clinician to grade the severity of the disease. Many sarcoidosis patients experience significant symptoms only with exertion and remain asymptomatic at rest $(3,4)$.

The American Thoracic Society (ATS), the European Thoracic Society (ETS), and the World Association of Sarcoidosis and Other Granulomatous Disorders (WASOG) have issued a joint statement (2) of recommendations for monitoring patients with thoracic sarcoidosis. The state-

Correspondence: A.J. Lopes, Rua Araguaia, 1266, Bloco 1/405, Frequesia/Jacarepaguá, 22745-271 Rio de Janeiro, RJ, Brasil.

E-mail: phel.lop@uol.com.br

Received July 2, 2011. Accepted February 6, 2012. Available online February 17, 2012. Published March 19, 2012. 
ment recommends that a chest radiograph and resting PFTs be performed regularly. Although these exams are considered to be sufficient to follow the evolution of the disease, they provide no information on the patients' functional capacity.

Therefore, in the present study, we sought to identify CPET measures that may be helpful in predicting the vital capacity and diffusion capacity outcomes of patients with thoracic sarcoidosis.

\section{Patients and Methods}

\section{Patients}

This was a longitudinal study involving 57 nonsmoking patients with thoracic sarcoidosis determined by a chest radiograph. The criteria for the diagnosis of sarcoidosis included compatible clinical, radiographic, and laboratory findings; histological evidence of noncaseating granuloma; the absence of mycobacterial infection, and no exposure to aerocontaminants or medication known to cause granulomatous disorders (2). Subjects with a medical history or laboratory findings of concomitant respiratory, cardiac or neuromuscular disease were excluded from the study. Participants were previously informed about the objective of the study and gave written informed consent according to current ethical standards. The study protocol was approved by the Research Ethics Committee of Hospital Universitário Pedro Ernesto, Universidade do Estado do Rio de Janeiro (Process No. 2273-CEP/HUPE).

\section{Study protocol and measurements}

The study consisted of two evaluations. At the first evaluation, in addition to chest radiographs, spirometry and the measurement of $D_{\text {LCOsb }}$ and CPET were performed on the patients. The severity of dyspnea was estimated using a standard 5-point scale (Medical Research Council): grade 0 = absent; grade 1 = hurrying on hills or after two flights of stairs; grade 2 = hurrying on flat ground or after one flight of stairs; grade 3 = breathlessness on minimal exertion, and grade 4 = breathlessness at rest (5). Five years later, the patients underwent the second evaluation of the study, consisting of another round of PFTs (spirometry and measurement of $D_{\text {LCOsb). }}$.

Each pair of chest radiographs was examined by two radiologists, who then reached a consensus about the final classification. The following classification was used: stage $0=$ no radiographic abnormalities; stage 1 = bilateral hilar adenopathy without parenchymal abnormalities; stage 2 = bilateral hilar adenopathy with interstitial parenchymal infiltrates; stage 3 = interstitial parenchymal infiltrates without hilar adenopathy, and stage 4 = cicatricial changes (6).

PFTs were completed using the Collins Plus Pulmonary Function Testing Systems (Warren E. Collins, USA) following the ATS standards for both the procedure and the interpretation (7). Maximum voluntary ventilation (MVV) was performed by coaching the patients to hyperventilate as vigorously as possible for $10 \mathrm{~s}$; the goal was a minimum frequency of 80 breaths $/ \mathrm{min}$, while the mobilized volume was recorded in liters per minute (8). The results are reported as a percent of the predicted values for the Brazilian population $(9,10)$.

Each subject performed symptom-limited maximal exercise testing using an electronically braked cycle ergometer connected to the Collins Plus Pulmonary Function Testing System. Following the collection of 2 to 5 min of resting data, subjects pedaled for $3 \mathrm{~min}$ at $60 \mathrm{rpm}$ without resistance, after which the work rate (WR) was incremented by 10 to $25 \mathrm{~W}$ each minute. The WR increment for each ramped exercise test was individualized based on each patient's pretest activity level; the objective was to achieve 8 to 12 min of progressive exercise before stopping (11). Heart rate $(\mathrm{HR})$ was monitored continuously using a 12-lead electrocardiogram monitor (Marquette Electronics, USA), and blood pressure measurements (Hewlett Packard, USA) were obtained every 2 min throughout the exercise and recovery periods. Oxygen saturation $\left(\mathrm{SpO}_{2}\right)$ was monitored noninvasively with a fiber optic earpiece oxymeter (Nonin Medical, USA). Oxygen desaturation during exercise was defined as a reduction of oxygen saturation greater than $4 \%$ from baseline values (12). Oxygen uptake $\left(\mathrm{VO}_{2}\right)$, carbon dioxide output $\left(\mathrm{VCO}_{2}\right)$, minute ventilation (VE), and related variables were calculated breath-by-breath. Arterial blood gas and lactate levels were measured (Roche Diagnostics, Brazil) at rest and at the end of the exercise period (peak performance) using samples taken from an indwelling radial arterial line. Breathing reserve was calculated as the difference between the measured resting MVV and the peak VE and is reported as a percentage of MVV [1 - (VE / MVV) $x$ 100]. Heart rate reserve was calculated as the difference between the peak and resting heart rates [(220 - age) - peak $\mathrm{HR}$ ]. The $\mathrm{VO}_{2}$ at the anaerobic threshold $\left(\mathrm{VO}_{2} \mathrm{\theta L}\right)$ was estimated using both the modified $\mathrm{V}$-slope and ventilator methods (13). The alveolar-arterial oxygen pressure gradient $\left(\mathrm{P}(\mathrm{A}-\mathrm{a}) \mathrm{O}_{2}\right)$ was calculated using the measured respiratory exchange ratio $\left(\mathrm{VCO}_{2} / \mathrm{VO}_{2}\right.$ or $\left.\mathrm{RER}\right)$ values. The values were compared to those predicted by Neder et al. (14) for the adult Brazilian population.

\section{Data analysis}

Data were analyzed using the SAS 6.11 software (SAS Inc., USA). Data are reported as the median and interquartile range values or frequencies (percentage). The KolmogorovSmirnov test was used to check the homogeneity of the sample. Peak $\mathrm{VO}_{2}$ was compared to various parameters using nonparametric testing, including the Mann-Whitney test, and Kruskal-Wallis analysis of variance followed by Dunn's multiple comparisons post-test. The relative variation of FVC and DLCOsb over the 5-year period was evaluated using the Wilcoxon signed-rank test. Correlations between the relative variation for the FVC and $D_{\text {LCOsb }}$ over a 5-year 
Table 1. Pulmonary function parameters and outcome measures of the cardiopulmonary exercise testing.

\begin{tabular}{|c|c|}
\hline Variables & $\begin{array}{c}\text { Median } \\
\text { (interquartile range) }\end{array}$ \\
\hline \multicolumn{2}{|l|}{ Pulmonary function parameters } \\
\hline FVC $(\%$ predicted $)$ & $95.5(82-105)$ \\
\hline $\mathrm{FEV}_{1}(\%$ predicted $)$ & $90(73-101)$ \\
\hline $\mathrm{FEV}_{1} / \mathrm{FVC}(\%)$ & $78.5(74-84)$ \\
\hline DLco (\% predicted) & $93.5(79-103)$ \\
\hline \multicolumn{2}{|c|}{ Cardiopulmonary exercise testing results } \\
\hline Peak VO 2 (\% predicted $)$ & $56.5(33-65)$ \\
\hline $\mathrm{VO}_{2} \theta \mathrm{L}(\%)$ & $41.5(30-55)$ \\
\hline RER max & $1.24(1.11-1.33)$ \\
\hline $\mathrm{O}_{2}$ pulse max (\% predicted) & $61.3(51.3-81.1)$ \\
\hline HRR (beats/min) & $47(34-54)$ \\
\hline BR max (breaths/min) & $41(34-56)$ \\
\hline Breathing reserve $(\%)$ & $45.6(13.9-62.6)$ \\
\hline $\mathrm{P}(\mathrm{A}-\mathrm{a}) \mathrm{O}_{2}(\mathrm{mmHg})$ & $18.6(15-36)$ \\
\hline$\Delta \mathrm{SpO}_{2}(\%)$ & $2.5(1-7)$ \\
\hline$\Delta$ blood lactate $(\mathrm{mM})$ & $1.86(1.13-3.21)$ \\
\hline
\end{tabular}

Data are reported as median (interquartile range) for 42 patients. $F V C=$ forced vital capacity; $F E V_{1}=$ forced expiratory volume in one second; DLco = carbon monoxide diffusing capacity; peak $\mathrm{VO}_{2}=$ peak oxygen uptake; $\mathrm{VO}_{2} \mathrm{\theta L}=\%$ peak $\mathrm{VO}_{2}$ at the estimated lactate threshold; RER max = maximum respiratory exchange ratio $\left(\mathrm{VCO}_{2} / \mathrm{VO}_{2}\right) ; \mathrm{O}_{2}$ pulse max = maximum oxygen pulse $\left(\mathrm{VO}_{2} /\right.$ heart rate); $\mathrm{HRR}=$ heart rate reserve; $\mathrm{BR}$ max = maximum respiratory rate; $\mathrm{P}(\mathrm{A}-\mathrm{a}) \mathrm{O}_{2}$ = alveolar-arterial oxygen pressure gradient at peak exercise; $\Delta \mathrm{SpO}_{2}=$ difference between peak and resting oxygen saturation; $\Delta$ blood lactate $=$ difference between peak and resting blood lactate.

period and the outcome measures of the CPET were studied using Spearman's rank correlation, with the exception of the correlation between breathing reserve and relative variations of FVC (logarithmic equation).

The clinical potential of the decline in pulmonary function to detect the potential factors related to outcome measures of the CPET was evaluated by means of receiver operating characteristic (ROC) analyses. Logistic regression was used for joint analysis to determine the factors that were independently related to the decreased pulmonary function. Only those variables found to be significant were retained in the model. Differences were considered to be significant when $\mathrm{P}<0.05$.

\section{Results}

Fifty-seven outpatients were evaluated. Fifteen were excluded due to a history of smoking (10), concomitant respiratory disease (2) and cardiac (2) or neuromuscular disease (1). Of the 42 patients studied, 22 (52.4\%) were females. Median age was 46.5 (39-53) years. When white subjects were considered separately from non-white subjects (Mu-
Table 2. Characteristics of the patients studied as well as the differences in peak oxygen uptake.

\begin{tabular}{lrl}
\hline Characteristics & $\mathrm{N}(\%)$ & $\begin{array}{c}\text { Peak VO } \\
\text { (\% predicted })\end{array}$ \\
\hline $\begin{array}{l}\text { Gender } \\
\text { Male }\end{array}$ & $20(47.6)$ & $59(36-67.5)$ \\
$\quad$ Female & $22(52.4)$ & $44(31-62)$ \\
Degree of dyspnea & & \\
0 & $14(33.3)$ & $59(38-65)$ \\
$1-2$ & $24(57.2)$ & $55(31-63)$ \\
$3-4$ & $4(9.5)$ & $41(29-58.5)$ \\
Receiving systemic therapy & & \\
Yes & $33(78.6)$ & $48.5(29-64)$ \\
No & $9(21.4)$ & $56.5(33-65)$ \\
Chest roentgenogram stage & & \\
1 & $5(11.9)$ & $60(60-61)$ \\
2 & $9(21.4)$ & $51(35-62)$ \\
3 & $23(54.8)$ & $62(32-69)$ \\
4 & $5(11.9)$ & $33(26-37)$ \\
\hline
\end{tabular}

Data are reported as number (\%) or median (interquartile range) for 42 patients. Peak $\mathrm{VO}_{2}=$ peak oxygen uptake. There were no statistically significant differences when comparing the patients' characteristics and peak oxygen uptake (Mann-Whitney test for gender and receiving systemic therapy, and Kruskal-Wallis analysis for degree of dyspnea and chest roentgenogram stage).

latto or Black), only 11 (26.2\%) described themselves as white. The time since the diagnosis of sarcoidosis in the 42 outpatients ranged from 1 to 360 months. Of the 42 subjects, $32(76.2 \%)$ had criteria for chronic disease (presence of the disease for 2 or more years) (2). Thirty-three patients $(78.6 \%)$ were receiving systemic therapy (corticosteroids alone or in combination with an immunosuppressive drug), which reflects the policy of the tertiary care clinic. However, no subject presented evidence of steroid toxicity.

Data from the pulmonary function studies and the CPET results at the first evaluation are summarized in Table 1. Thirty-seven of the 42 patients $(88.1 \%)$ failed to reach at least $80 \%$ of their predicted peak $\mathrm{VO}_{2}$. Arterial oxygen desaturation occurred with exercise in 20 patients $(47.6 \%)$, while a breathing reserve of less than $25 \%$ was observed in 17 patients $(40.5 \%)$. Fifteen patients $(35.7 \%)$ had a $\mathrm{P}(\mathrm{A}-\mathrm{a})$ $\mathrm{O}_{2}(\mathrm{mmHg})$ value greater than $35 \mathrm{mmHg}$.

The characteristics of the patients, along with the peak $\mathrm{VO}_{2}$ value for the different patient groups, are listed in Table 2. Females reached a lower peak $\mathrm{VO}_{2}$ than males, but the difference was not statistically significant. While patients diagnosed with higher chest roentgenogram stage generally displayed a lower peak $\mathrm{VO}_{2}$, the association between the radiographic stage and peak $\mathrm{VO}_{2}$ was not statistically significant. Patients receiving therapy tended to achieve a lower peak $\mathrm{VO}_{2}$, but the difference was not statistically significant. 
Five years after the first evaluation, FVC\% and $\mathrm{D}_{\text {LCOsb }} \%$ were significantly decreased [95.5 (82-105) vs 87.5 (58103) and 93.5 (79-103) vs 84.5 (44-102), respectively; $P<$ $0.0001]$. The relative variation of FVC and $D_{\text {LCOsb }}$ between the first and the second assessment was $-5.1 \%(-23.1-0 \%)$ and $-2.5 \%(-44.4-0.93 \%)$, respectively. The median interval between measurements was 61.5 months (range: 55-67 months). In this second evaluation, 26 patients $(61.9 \%)$ were under systemic therapy (treatment decisions were taken according by the treating physician). The relative variations of FVC and $D_{\text {LCOsb }}$ did not differ significantly between subjects receiving therapy or not at the time of follow-up evaluation.

We compared the relative variations of the pulmonary function tests with the CPET measures. The results of univariate analysis are given in Table 3 and Figure 1. Among the variables studied, peak $\mathrm{VO}_{2}$, maximum respiratory rate (BR max), breathing reserve, $\mathrm{P}(\mathrm{A}-\mathrm{a}) \mathrm{O}_{2}$ max, and $\Delta \mathrm{SpO}_{2}$ values showed a better correlation.

A significant decline in pulmonary function (a decrease of $\geq 10 \%$ from the initial FVC values or a decrease of $\geq 15 \%$ from the values initially measured in the $D_{\text {LCOsb }}$ ) was observed in 18 outpatients; a decrease in both FVC and D LCOsb was observed in 17 patients. According to this criterion, the values for the area under the ROC curve identified the following optimal cut-off points: peak $\mathrm{VO}_{2}$ $\leq 50 \%$ of the predicted value; $\mathrm{BR} \max \geq 40$ breaths $/ \mathrm{min}$; breathing reserve $\leq 40 \% ; \mathrm{P}(\mathrm{A}-\mathrm{a}) \mathrm{O}_{2} \geq 22 \mathrm{mmHg}$, and $\Delta$ $\mathrm{SpO}_{2} \geq 4 \%$. Table 4 shows the baseline CPET results for
42 patients according to the decline in pulmonary function after a 5-year follow-up.

We also investigated whether outcome measures of the CPET would demonstrate an independent role in predicting the decline of pulmonary function. All variables were assessed in a forward stepwise logistic regression model. In the model, a $\mathrm{P}(\mathrm{A}-\mathrm{a}) \mathrm{O}_{2} \geq 22 \mathrm{mmHg}$ and a breathing reserve $\leq 40 \%$ were identified as significant and independent variables (Table 5).

\section{Discussion}

This study evaluated the role of CPET as a predictor of the decline in pulmonary function after a 5-year follow-up in a sample of 42 nonsmoking patients with sarcoidosis. To our knowledge, no study has previously conducted a similar evaluation in this patient subset.

A 2-year follow-up period has been considered a standard time to determine the outcome of sarcoidosis $(15,16)$. However, in order to define the clinical phenotypes of the disease, WASOG developed a recent task force using a 5-year follow-up period (17). Compared to the 2-year follow-up outcome, nearly one-quarter of the patients had a different clinical outcome after 5 years. Thus, the 5-year follow-up period is an important methodological characteristic of our study.

The main findings of this research were as follows. First, we observed that FVC and DLCOsb significantly decreased after a 5-year follow-up in patients with thoracic

Table 3. Univariate analysis comparing the relative variations of pulmonary function tests and cardiopulmonary exercise testing measures.

\begin{tabular}{|c|c|c|c|c|}
\hline \multirow[t]{2}{*}{ Variables } & \multicolumn{2}{|c|}{$\begin{array}{l}\text { Relative variations of FVC } \\
\text { ( } \% \text { of predicted })\end{array}$} & \multicolumn{2}{|c|}{$\begin{array}{l}\text { Relative variations of } D_{\mathrm{LCOsb}} \\
\quad(\% \text { of predicted })\end{array}$} \\
\hline & Correlation coefficient & $\mathrm{P}$ & Correlation coefficient & $\mathrm{P}$ \\
\hline Peak $\mathrm{VO}_{2}(\%$ predicted $)$ & 0.764 & $<0.0001$ & 0.803 & $<0.0001$ \\
\hline $\mathrm{VO}_{2} \theta \mathrm{L}(\%)$ & -0.159 & 0.32 & -0.143 & 0.37 \\
\hline RER max & -0.238 & 0.13 & -0.221 & 0.16 \\
\hline $\mathrm{O}_{2}$ pulse $\max (\%$ predicted $)$ & -0.046 & 0.77 & -0.038 & 0.81 \\
\hline HRR (beats/min) & -0.246 & 0.12 & -0.225 & 0.15 \\
\hline BR max (breaths/min) & -0.813 & $<0.0001$ & -0.685 & $<0.0001$ \\
\hline Breathing reserve (\%) & 0.887 & $<0.0001$ & 0.795 & $<0.0001$ \\
\hline $\mathrm{P}(\mathrm{A}-\mathrm{a}) \mathrm{O}_{2}(\mathrm{mmHg})$ & -0.781 & $<0.0001$ & -0.765 & $<0.0001$ \\
\hline$\Delta \mathrm{SpO}_{2}(\%)$ & -0.752 & $<0.0001$ & -0.707 & $<0.0001$ \\
\hline$\Delta$ blood lactate $(\mathrm{mM})$ & 0.002 & 0.99 & -0.071 & 0.66 \\
\hline
\end{tabular}

$\mathrm{FVC}=$ forced vital capacity; $\mathrm{D}_{\mathrm{LCO}} \mathrm{sb}=$ single-breath diffusion of carbon monoxide across the lung; peak $\mathrm{VO}_{2}=$ peak oxygen uptake; $\mathrm{VO}_{2} \theta \mathrm{L}=\%$ peak $\mathrm{VO}_{2}$ at the estimated lactate threshold; $\mathrm{RER}$ max = maximum respiratory exchange ratio $\left(\mathrm{VCO}_{2} / \mathrm{VO}_{2}\right) ; \mathrm{O}_{2}$ pulse max = maximum oxygen pulse $\left(\mathrm{VO}_{2}\right.$ /heart rate); $\mathrm{HRR}=$ heart rate reserve; $\mathrm{BR}$ max = maximum respiratory rate; $\mathrm{P}(\mathrm{A}-\mathrm{a}) \mathrm{O}_{2}$ $=$ alveolar-arterial oxygen pressure gradient at peak exercise; $\Delta \mathrm{SpO}_{2}=$ difference between peak and resting oxygen saturation; $\Delta$ blood lactate $=$ difference between peak and resting blood lactate. Correlation coefficient was determined by Spearman's rank correlation for all variables, except for the correlation between breathing reserve and relative variations of FVC (logarithmic equation). 

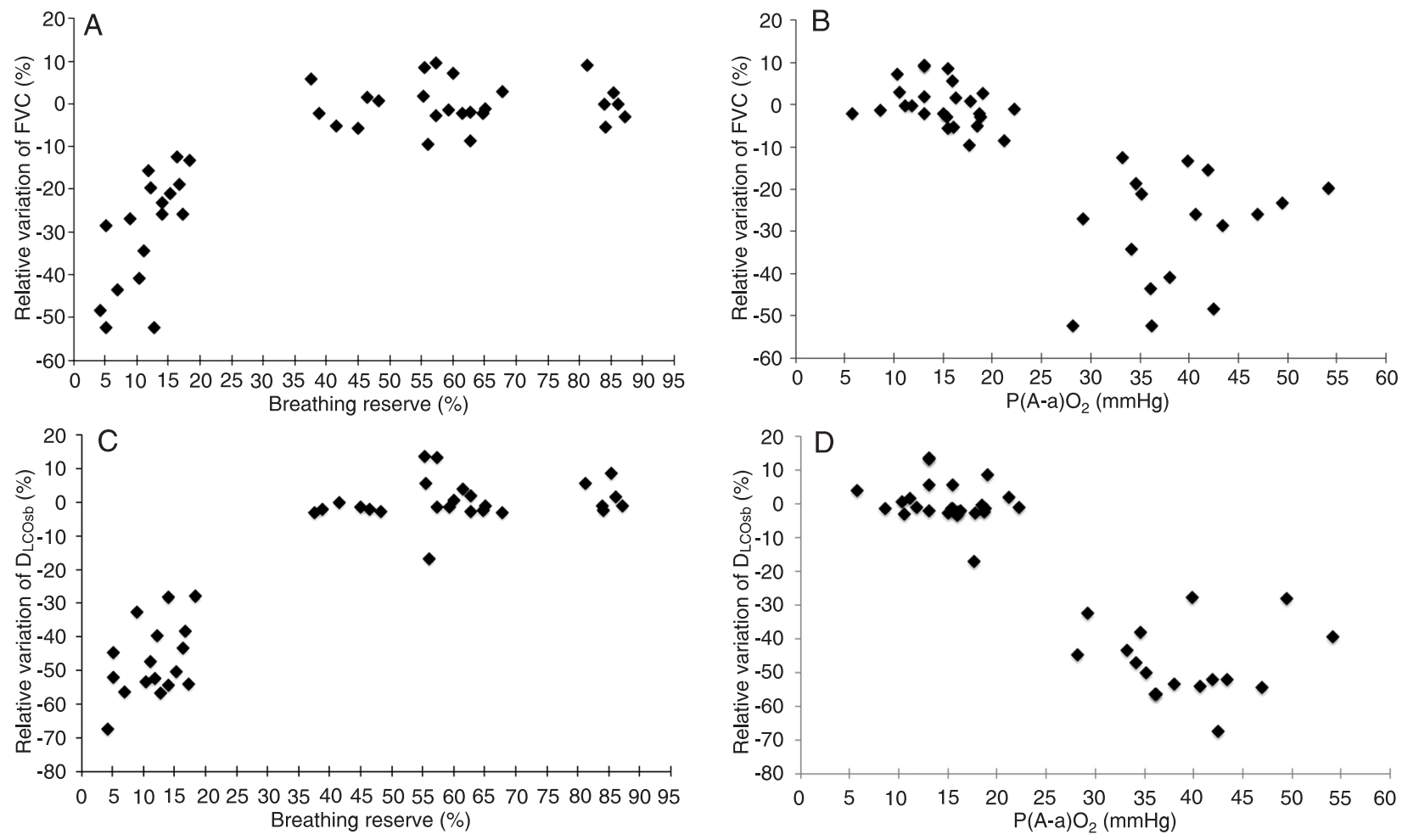

Figure 1. Relationship of relative variation of forced vital capacity $(F V C)$ over a 5 -year period with the breathing reserve $\left(r^{2}=0.887 ; P\right.$ $<0.0001)(P a n e l A)$ and the alveolar-arterial oxygen pressure gradient $\left[\mathrm{P}(\mathrm{A}-\mathrm{a}) \mathrm{O}_{2}\right]$ at peak exercise $(\rho=-0.781 ; \mathrm{P}<0.0001)(P a n e l B)$ obtained by cardiopulmonary exercise testing. Relationship of relative variation of single-breath diffusion of carbon monoxide across the lung $\left(D_{\text {LCOsb }}\right)$ over a 5-year period with the breathing reserve $(\rho=0.795 ; P<0.0001)(P a n e l C)$ and the $P(A-a) O_{2}$ at peak exercise $(\rho=-0.765 ; P<0.0001)(P a n e l D)$ obtained by cardiopulmonary exercise testing. Correlation was determined by univariate analysis using Spearman's rank correlation (Panels $B, C$ and $D$ ), with the exception of the correlation between breathing reserve and relative variations of FVC (logarithmic equation; Panel $A$ ).

Table 4. Results of cardiopulmonary exercise testing according to the decline in pulmonary function after a 5-year follow-up in thoracic sarcoidosis patients.

\begin{tabular}{|c|c|c|c|c|c|c|}
\hline \multirow[t]{3}{*}{ Significant variables* } & \multicolumn{6}{|c|}{ Decline in pulmonary function ${ }^{+}$} \\
\hline & \multicolumn{2}{|c|}{ Present $(\mathrm{N}=18)$} & \multicolumn{2}{|c|}{ Absent $(N=24)$} & \multirow[t]{2}{*}{$\mathrm{RR}$} & \multirow[t]{2}{*}{$95 \% \mathrm{Cl}$} \\
\hline & $\mathrm{N}$ & $\%$ & $\mathrm{~N}$ & $\%$ & & \\
\hline Peak $\mathrm{VO}_{2} \leq 50 \%$ of predicted & 17 & 94.4 & 2 & 8.3 & 20.6 & $3.01-140.8$ \\
\hline BR max $\geq 40$ breaths/min & 16 & 88.9 & 6 & 25.0 & 7.27 & $1.91-27.8$ \\
\hline Breathing reserve $\leq 40 \%$ & 17 & 94.4 & 2 & 8.3 & 20.6 & $3.01-140.8$ \\
\hline $\mathrm{P}(\mathrm{A}-\mathrm{a}) \mathrm{O}_{2} \geq 22 \mathrm{mmHg}$ & 17 & 94.4 & 1 & 4.2 & 22.7 & $3.32-154.9$ \\
\hline$\Delta \mathrm{SpO}_{2} \geq 4 \%$ & 17 & 94.4 & 3 & 12.5 & 18.7 & $2.73-128.0$ \\
\hline
\end{tabular}

$\mathrm{RR}=$ relative risk $; 95 \% \mathrm{Cl}=95 \%$ confidence interval; peak $\mathrm{VO}_{2}=$ peak oxygen uptake; $\mathrm{BR}$ max = maximum respiratory rate; $\mathrm{P}(\mathrm{A}-\mathrm{a}) \mathrm{O}_{2}=$ alveolar-arterial oxygen pressure gradient at peak exercise; $\Delta \mathrm{SpO}_{2}=$ difference between peak and resting oxygen saturation. ${ }^{*}$ Significant variables resulting from Spearman's rank correlation between the relative variations of pulmonary function tests and cardiopulmonary exercise testing measures (optimal cut-off points of the area under the ROC curve). ${ }^{+}$Decrease $>10 \%$ in relation to the initial values of forced vital capacity or single-breath diffusion of carbon monoxide across the lung. 
Table 5. Forward stepwise regression analysis: relationship between the decline in pulmonary function and study variables.

\begin{tabular}{|c|c|c|c|c|c|c|}
\hline \multirow[t]{2}{*}{ Outcome variable } & \multirow[t]{2}{*}{ Independent variables } & \multicolumn{2}{|c|}{ Unstandardized coefficient } & \multirow[t]{2}{*}{$\mathrm{P}$} & \multirow[t]{2}{*}{$\mathrm{RR}$} & \multirow[t]{2}{*}{$95 \% \mathrm{Cl}$} \\
\hline & & $\mathrm{B}$ & SE & & & \\
\hline \multirow[t]{2}{*}{ Decline in pulmonary function* } & $\mathrm{P}(\mathrm{A}-\mathrm{a}) \mathrm{O}_{2} \geq 22 \mathrm{mmHg}$ & 4.25 & 1.60 & 0.001 & 70.0 & $3.03-161.3$ \\
\hline & Breathing reserve $\leq 40 \%$ & 3.03 & 1.63 & 0.014 & 20.8 & $0.85-507.6$ \\
\hline
\end{tabular}

$\mathrm{SE}=$ standard error; $\mathrm{RR}=$ relative risk $; 95 \% \mathrm{Cl}=95 \%$ confidence interval; $\mathrm{P}(\mathrm{A}-\mathrm{a}) \mathrm{O}_{2}=$ alveolar-arterial oxygen pressure gradient at peak exercise. ${ }^{*}$ Decrease of $>10 \%$ from the values initially measured in the forced vital capacity or in the single-breath diffusion of carbon monoxide across the lung.

sarcoidosis ( $P<0.0001$ for both). Second, a spectrum of ventilatory and pulmonary gas exchange abnormalities obtained in the CPET was associated with the reduction in FVC and $D_{\text {LCOsb }}$ five years later. In addition, we determined the cut-off of the CPET measures responsible for a significant decline in pulmonary function and demonstrated that $\mathrm{P}(\mathrm{A}-\mathrm{a}) \mathrm{O}_{2}$ and breathing reserve were independent predictors of functional impairment.

Winterbauer and Hutchinson (18) reported a reduction in FVC and $\mathrm{D}_{\mathrm{LCOsb}}$ in more than two thirds of patients (discordant changes occurred in fewer than $5 \%$ of patients). However, in contrast to these authors, we found a higher relative variation of $D_{L C O s b}$ when considering the two study time points. In sarcoidosis, the reduction of $D_{\mathrm{LCOsb}}$ may reflect impairments of the gas exchange area, barrier thickness, or ventilation-perfusion-diffusion mismatching of the lung (19). Interestingly, $D_{\text {LCOsb }}$ has also been found to be fairly correlated with gas exchange abnormalities during exercise and in particular to be the best predictive and sensitive index of a fall in $\mathrm{PaO}_{2}$ (8).

Exercise testing is a remarkably robust and versatile tool that provides valuable diagnostic and prognostic information regarding patients with pulmonary diseases (20). A low peak $\mathrm{VO}_{2}$ is usually the starting point in the evaluation of reduced exercise capacity. In our study, approximately $90 \%$ of patients failed to reach at least $80 \%$ of peak $\mathrm{VO}_{2}(\%$ predicted) at the initial evaluation. Interestingly, peak $\mathrm{VO}_{2}$ showed a significant correlation with the relative variations of both FVC and DLco $(P<0.0001)$. However, changes in $\mathrm{VO}_{2}$ can be due to multiple factors, including gas exchange across the lung, the oxygen content of blood, oxygen delivery to tissues, and the oxygen uptake in the tissues (13).

Patients with significant interstitial lung disease often display low breathing reserve and arterial desaturation during exercise. In the present study, these two variables correlated with the decline in pulmonary function at the 5 -year follow-up. Because the majority of patients in this sample $(66.7 \%)$ had radiographic stages 3 and 4 at the initial evaluation may reflect a limitation by ventilatory mechanisms (21). Moreover, ventilatory abnormalities during CPET have been reported in up to $47 \%$ of sarcoidosis patients $(11,22)$. The ventilatory stress (demand/capacity) for a given work rate is much greater in patients with interstitial lung disease than in normal subjects. Additionally, it is possible that the exercise limitation in these patients is due to the marked arterial oxygen desaturation, which usually develops during exercise. Arterial hypoxemia can impair exercise tolerance because of inadequate oxygen delivery to working muscles (23).

The persistence of abnormal pulmonary gas exchange is related to a poor prognosis and is an important criterion indicating long-term steroid therapy (2). Eklund et al. (24) showed that diffusion limitation contributed up to $50 \%$ of the $\mathrm{P}(\mathrm{A}-\mathrm{a}) \mathrm{O}_{2}$ widening during exercise in sarcoidosis patients; these investigators found only a moderate degree of ventilation-perfusion mismatch. In the present study, we found a significant correlation between $\mathrm{P}(\mathrm{A}-\mathrm{a}) \mathrm{O}_{2}$ and the relative variations of both FVC and DLco $(P<0.0001)$. At rest, the apical regions of the lung contribute relatively little to ventilation and gas exchange; however, during exercise, apical pulmonary circulation is normally recruited and contributes significantly to the capacity of the lung to increase the rate of gas exchange. Because the lesions of sarcoidosis favor the upper lobes of the lungs, lung function measured during exercise may have a higher sensitivity for detecting the presence and progression of parenchymal disease (25).

Using logistic regression analysis of the independent factors affecting the decline of pulmonary function at the 5-year follow-up, the only predictive factors were $\mathrm{P}(\mathrm{A}-\mathrm{a}) \mathrm{O}_{2}$ $\geq 22 \mathrm{mmHg}$ and breathing reserve $\leq 40 \%$, in that order. In fact, the $\mathrm{P}(\mathrm{A}-\mathrm{a}) \mathrm{O}_{2}$ value during exercise has been found to be the best pulmonary gas exchange impairment index in sarcoidosis patients, showing associations with both DLco and FVC $(8,12)$. Kollert et al. (26) performed a retrospective study to determine the extent to which the gas exchange measurement during exercise reflects disease activity and the clinical course of sarcoidosis. They showed that the $\mathrm{P}(\mathrm{A}-\mathrm{a}) \mathrm{O}_{2}$ during exercise represents disease activity and its extent and is associated with a prolonged need for immunosuppressive treatment during follow-up care in patients with pulmonary sarcoidosis. In interstitial lung disease, a 
smaller pulmonary vascular bed reserve is available for recruitment, limiting the increase in lung surface area for gas exchange during exercise. Hence, both mixed venous oxygen tension and arterial oxygen tension drop with the progressively increasing workload and increased drop of peripheral oxygen uptake (8). Regarding the breathing reserve, patients with more advanced stages of interstitial lung disease often display higher levels of minute ventilation than those observed in normal subjects during exercise. These higher levels are largely due to the increased dead space ventilation; however, other contributing mechanisms responsible for this heightened ventilatory response may include inputs from mechanoreceptors and chemoreceptors and mediators of inflammation (3).

The present investigation has some limitations. First, there was, by definition, a selection bias because the study was performed at a tertiary hospital to which patients with severe complaints and advance stages of sarcoidosis are more likely to be referred. In fact, 32 patients $(76.2 \%)$ had criteria for the definition of chronic disease. Second, in 17 of 42 patients $(40.1 \%)$, the $\mathrm{VO}_{2} \mathrm{\theta L}$ was low, and the $\mathrm{O}_{2}$ pulse max was abnormal, suggesting cardiocirculatory

\section{References}

1. Abehsera $M$, Valeyre $D$, Grenier $P$, Jaillet $H$, Battesti JP, Brauner MW. Sarcoidosis with pulmonary fibrosis: CT patterns and correlation with pulmonary function. AJR Am J Roentgenol 2000; 174: 1751-1757.

2. Statement on sarcoidosis. Joint Statement of the American Thoracic Society (ATS), the European Respiratory Society (ERS) and the World Association of Sarcoidosis and Other Granulomatous Disorders (WASOG) adopted by the ATS Board of Directors and by the ERS Executive Committee, February 1999. Am J Respir Crit Care Med 1999; 160: 736-755.

3. Marciniuk DD, Gallagher CG. Clinical exercise testing in interstitial lung disease. Clin Chest Med 1994; 15: 287-303.

4. Weisman IM, Zeballos RJ. Clinical exercise testing. Clin Chest Med 2001; 22: 679-701, viii.

5. Xaubet A, Rodriguez-Roisin R, Bombi JA, Marin A, Roca J, Augusti-Vidal A. Correlation of bronchoalveolar lavage and clinical and functional findings in asbestosis. Am Rev Respir Dis 1986; 133: 848-854.

6. Scadding JG. Prognosis of intrathoracic sarcoidosis in England. A review of 136 cases after five years' observation. $\mathrm{Br}$ Med J 1961; 2: 1165-1172.

7. Standardization of Spirometry, 1994 Update. American Thoracic Society. Am J Respir Crit Care Med 1995; 152: 1107-1136.

8. Medinger AE, Khouri S, Rohatgi PK. Sarcoidosis: the value of exercise testing. Chest 2001; 120: 93-101.

9. Pereira CA, Sato T, Rodrigues SC. New reference values for forced spirometry in white adults in Brazil. J Bras Pneumol 2007; 33: 397-406.

10. Neder JA, Andreoni S, Peres C, Nery LE. Reference values for lung function tests. III. Carbon monoxide diffusing capacity (transfer factor). Braz J Med Biol Res 1999; 32: dysfunction (12). Although some patients may have had cardiac sarcoidosis or pulmonary hypertension, we did not directly determine cardiac circulatory status; thus, this can be considered a limitation of the study. A new CPET in the second evaluation could also have helped to define the cases difficult to interpret. Finally, the conclusion was based on a small number of patients, resulting in high values for relative risk and longer intervals for the $95 \%$ confidence interval in the logistic regression model. Carefully controlled prospective studies conducted on a larger sample are required to confirm these preliminary results and to validate our prediction model. In future studies, a number of potential prognostic variables, including clinical and radiological findings, may also be tested along with the CPET variables.

Patients with thoracic sarcoidosis showed significant reductions in FVC and $D_{\text {LCOsb }}$ at the 5-year follow-up. Additionally, the outcome measures of the CPET (P(A-a) $\mathrm{O}_{2}$ and breathing reserve) were predictors of a decline in pulmonary function. Determining the CPET measures may be helpful in predicting the outcomes of patients with thoracic sarcoidosis.
729-737.

11. Sietsema KE, Kraft M, Ginzton L, Sharma OP. Abnormal oxygen uptake responses to exercise in patients with mild pulmonary sarcoidosis. Chest 1992; 102: 838-845.

12. Gibbons WJ, Levy RD, Nava S, Malcolm I, Marin JM, Tardif $\mathrm{C}$, et al. Subclinical cardiac dysfunction in sarcoidosis. Chest 1991; 100: 44-50.

13. Barros WG, Neder JA, Pereira CA, Nery LE. Clinical, radiographic and functional predictors of pulmonary gas exchange impairment at moderate exercise in patients with sarcoidosis. Respiration 2004; 71: 367-373.

14. Neder JA, Nery LE, Castelo A, Andreoni S, Lerario MC, Sachs A, et al. Prediction of metabolic and cardiopulmonary responses to maximum cycle ergometry: a randomised study. Eur Respir J 1999; 14: 1304-1313.

15. Baughman RP, Shipley R, Eisentrout CE. Predictive value of gallium scan, angiotensin-converting enzyme level, and bronchoalveolar lavage in two-year follow-up of pulmonary sarcoidosis. Lung 1987; 165: 371-377.

16. Judson MA, Baughman RP, Thompson BW, Teirstein AS, Terrin ML, Rossman MD, et al. Two year prognosis of sarcoidosis: the ACCESS experience. Sarcoidosis Vasc Diffuse Lung Dis 2003; 20: 204-211.

17. Baughman RP, Nagai $S$, Balter M, Costabel U, Drent M, du Bois $\mathrm{R}$, et al. Defining the clinical outcome status (COS) in sarcoidosis: results of WASOG Task Force. Sarcoidosis Vasc Diffuse Lung Dis 2011; 28: 56-64.

18. Winterbauer RH, Hutchinson JF. Use of pulmonary function tests in the management of sarcoidosis. Chest 1980; 78: 640-647.

19. Lamberto $\mathrm{C}$, Nunes $\mathrm{H}$, Le Toumelin $\mathrm{P}$, Duperron F, Valeyre $D$, Clerici C. Membrane and capillary blood components of 
diffusion capacity of the lung for carbon monoxide in pulmonary sarcoidosis: relation to exercise gas exchange. Chest 2004; 125: 2061-2068.

20. Arena R, Sietsema KE. Cardiopulmonary exercise testing in the clinical evaluation of patients with heart and lung disease. Circulation 2011; 123: 668-680.

21. Baughman RP, Teirstein AS, Judson MA, Rossman MD, Yeager $\mathrm{H}$ Jr, Bresnitz EA, et al. Clinical characteristics of patients in a case control study of sarcoidosis. Am J Respir Crit Care Med 2001; 164: 1885-1889.

22. Miller A, Brown LK, Sloane MF, Bhuptani A, Teirstein AS. Cardiorespiratory responses to incremental exercise in sarcoidosis patients with normal spirometry. Chest 1995; 107: 323-329.
23. Marciniuk DD, Watts RE, Gallagher CG. Dead space loading and exercise limitation in patients with interstitial lung disease. Chest 1994; 105: 183-189.

24. Eklund A, Broman L, Broman M, Holmgren A. V/Q and alveolar gas exchange in pulmonary sarcoidosis. Eur Respir J 1989; 2: 135-144.

25. Arcasoy SM, Christie JD, Pochettino A, Rosengard BR, Blumenthal NP, Bavaria JE, et al. Characteristics and outcomes of patients with sarcoidosis listed for lung transplantation. Chest 2001; 120: 873-880.

26. Kollert F, Geck B, Suchy R, Jorres RA, Arzt M, Heidinger $D$, et al. The impact of gas exchange measurement during exercise in pulmonary sarcoidosis. Respir Med 2011; 105: $122-129$. 